\title{
Chapter 4 \\ Haiti's National HIV Quality Management Program and the Implementation of an Electronic Medical Record to Drive Improvement in Patient Care
}

\author{
Joshua Bardfield, Bruce D. Agins, Margareth Jasmin, Nicasky Celestin, \\ Nirva Duval, Jean Gabriel Balan, Patrice Joseph, Jean Solon Valles, \\ and Yves Marie Bernard
}

\begin{abstract}
This case describes the development and application of a national electronic medical record system, iSanté, to drive improvement as part of Haiti's national HIV quality management program. The Haiti Ministry of Health, with support from donor agencies and local implementing partners, developed iSanté in 2008 to support public health, specifically to facilitate and prioritize use of data for quality improvement and real-time monitoring of HIV care and treatment nationwide. This case describes the development and implementation of the HIV quality management program at the facility level and the development of the iSanté electronic medical record system to record and tabulate data to facilitate evidence-based decision-making about patient care in order to improve patient outcomes.
\end{abstract}

\footnotetext{
J. Bardfield $(\triangle)$

Bard College, Formerly with HEALTHQUAL, Annandale-On-Hudson, NY, USA

e-mail: jbardfield@bard.edu

B. D. Agins

HEALTHQUAL, Institute for Global Health Sciences, University of California San Francisco (UCSF), New York, NY, USA
}

M. Jasmin

HEALTHQUAL-Haiti, Port-au-Prince, Haiti

N. Celestin

U.S. Centers for Disease Control and Prevention (CDC), Port-au-Prince, Haiti

N. Duval

Ministry of Health and Population, Port-au-Prince, Haiti

J. G. Balan

ITECH-Haiti, Port-au-Prince, Haiti

P. Joseph $\cdot$ J. S. Valles $\cdot$ Y. M. Bernard

CDC, Port-au-Prince, Haiti 
Keywords Electronic medical record · Haiti · HIV · Prevention of mother-to-child transmission $\cdot$ Quality management $\cdot$ Retention

\section{Introduction}

HIV/AIDS first emerged in Haiti in the late 1970s, an era of minimal defenses against the onset of the emerging epidemic. By 2016, there were 150,000 people living with HIV in Haiti (prevalence of 1.7\% 15-49 years), with only a little over half receiving antiretroviral therapy (UNAIDS 2016). Key affected populations include sex workers (8.4\% prevalence), men who have sex with men (18.2\% prevalence), and incarcerated people (4.3\% prevalence) (UNAIDS 2016).

As a response to the HIV/AIDS epidemic, in 2007 the country's Ministry of Health (Ministère de la Santé Publique et de la Population, MSPP), with funding from the US President's Emergency Plan for AIDS Relief (PEPFAR) through the US Centers for Disease Control and Prevention (CDC) and in coordination with other donor agencies and local implementing partners, initiated a national HIV quality management program, HEALTHQUAL-Haiti, to systematically measure and improve the quality of adult and pediatric HIV care and treatment services.

\section{Designing the Improvement Effort}

\section{Haiti's Quality Management Program}

In 2007, the MSPP launched the national HIV quality management program with PEPFAR support at 19 clinics focusing on adult and pediatric HIV care, initially using paper-based records; it was later expanded to a total of $135 \mathrm{HIV}$ clinics nationally. In 2012, the national HIV quality management program expanded its focus beyond HIV to include other public health priorities, including maternal and child health, nutrition, and mental health. At that time, the program increased the number of quality measures collected from the initial 10-19 indicators, which were revised and expanded to cover outcomes and processes of care for HIV-TB comorbidity, maternal health, immunization, nutrition, and mental health.

The quality management program implemented by the Haiti MSPP is based on a public health approach to government-led HIV improvement programs developed in 1992 by the New York State Department of Health AIDS Institute (Agins et al. 1995) and now implemented in 10 countries in Africa, Asia, South America, the Caribbean, and the South Pacific (UCSF-HEALTHQUALa). 
The quality management program encompasses the structures, functions, and processes required to support sustainable implementation of quality care at the national level including:

- Leadership involvement

- Development of a national quality management plan, workplan, and sustainability plan

- Human resource management

- Patient and community involvement

- Performance measurement: collecting, reviewing, analyzing, and using data for improvement

- Organizational infrastructure (including management committees, systems for QI documentation, and national QI projects)

- Knowledge management and peer exchange

- Capacity building, including coaching, mentoring, and training

- Patient safety

- Focus on patient outcomes

Quality improvement coaching is a key component of a national Quality Management Program and imperative for the deployment of any large-scale improvement initiative. Coaching is the primary strategy through which the national Quality Management Program develops, enhances, and refines systems at site level to improve health-care processes and patient outcomes. In Haiti, an initial cadre of 19 coaches was trained by experienced quality improvement advisors/coaches using a formal training continuum that included Training of Trainers, Training on Coaching Basics, and Training of Quality Leaders didactic and experiential modules (UCSF-HEALTHQUALb). The trainings were facilitated through funding from PEPFAR with the support of the MSPP, the national HIV program, and implementing partners and included capacity building support in key areas of improvement (rooted in the model for improvement) (Langley et al. 2009):

- Performance measurement, including data collection, analysis, and reporting

- Quality improvement, including:

- Reviewing and analyzing performance data

- Developing project teams

- Investigating the process (root cause analysis)

- Planning and testing changes/improvement strategies, using the plan-dostudy-act (PDSA) improvement cycle or more formal implementation strategies

- Evaluating and adapting changes and developing sustainability plans

- The elements of the quality management program

This first group of coaches then trained and coached the first group of 19 facilities that were selected to be part of Haiti's national HIV quality management 
program. These facilities were selected to include a diverse mix of facility types and sizes (hospital, clinic, community health center) and geographic areas (urban/ rural and departmental region). As the program expanded, coaches were assigned to facilities based on the facility's needs in the three core areas noted aboveperformance measurement, quality improvement, and the quality management program. Gradually, new coaches from the MSPP and implementing partners were trained as new facilities were integrated into the HIV quality management program.

Coaches come from diverse professional backgrounds-medical and paramedical, information system, program management, etc.- - and are all trained using the previously mentioned training continuum and a more recently developed formal coaching curriculum for QI (http://www.healthqual.org/coaching-toolkit). Coaches are generally recruited from within the health sector and often from within the MSPP, implementing partners' or donor agencies' staff.

Coaches can be assigned to one or more facilities depending on seniority. The implementing partners' coaches are assigned to facilities supported by that partner. The CDC regional coaches and the MSPP Departmental coaches support all facilities in the region/district where they are assigned. Even if a coach is assigned to a specific facility, they usually plan joint visits with other coaches-especially when conducting the organizational assessment, which is a formal validated scoring tool that measures facility-level progress in core areas of the quality management program. The coaches are encouraged to work together to ensure harmonization of improvement activities across the national program.

Coaches visit each facility at least once every quarter. These visits can occur more often depending on need, level of engagement, performance, and staff turnover. Visits are generally scheduled but can happen ad hoc, if needed. In the beginning, the HIV quality management program focused primarily on improving HIV care, and coaches generally focused their technical assistance efforts in that area. As the quality management program transitioned to a broader public health approach, designed to leverage improvement principles from HIV to other infectious and chronic diseases across the health system, QI training and support have expanded to all the facility personnel. All facility-based programs can be involved in QI depending on facility performance and priorities.

In addition, the MSPP established a national-level Core Team, comprised of MSPP staff and implementing partners and led by the MSPP General Director, to act as the executive arm of the national quality management program. The Core Team provides support, guidance, and technical assistance to the national HIV quality program. National QI projects, in which the MSPP identifies national priorities for clinics to target their QI activities, are selected by the Core Team according to epidemiologic data, PEPFAR recommendations, and gaps identified in the facility performance reports, which are generated by each facility based on patientlevel data. 


\section{Implementing the Quality Management Program at the Facility Level}

As a first step in the implementation of the HIV quality management program at the facility level, an organizational assessment ${ }^{1}$ is conducted to identify programmatic gaps and weaknesses. Based on findings from the assessment and informed by recommendations shared by QI coaches, the facility leadership and staff develop a formal quality plan and workplan to address those gaps. Next, based on clinic resources, a formal Quality Committee may be formed to manage QI activities. The Quality Committee is usually tasked with reviewing data and selecting facility-level QI projects to be conducted, with consideration of national priorities. The Quality Committee also selects the members of the QI teams. At the facility level, QI teams are comprised of existing facility staff.

Once a facility is integrated into the national HIV quality management program, the staff are trained on QI methodology. Initial training happens at formal training sessions, which typically include multiple facilities, with 2-4 personnel from each participating facility. Subsequent training to spread QI knowledge to all staff takes place on-site at the facility and is led by the coaches. The QI coaches provide experiential training at the facility level in each of the key areas of improvement listed above, which prepares a facility to move a quality improvement project through each step from initiation to completion and enables them to repeat the process with new opportunities identified for improvement.

Facility-based QI projects are selected based on facility performance data, national priorities, and feasibility based on human resources at a given facility. Once iSanté was introduced, performance data could be readily extracted from the platform and reviewed by the facility team. The facility-based QI project team would then conduct process analysis, often using a fishbone diagram, to diagnose the underlying causes of gaps in their processes and systems of care delivery and suggest effective and sustainable strategies for change that are tested through PDS cycles. Successful strategies are then adopted after approval of the Quality Committee and the facility leadership.

\section{Developing an Electronic Medical Record System in Haiti}

Systematic collection of routine patient-level clinical data in health-care facilities in low- and middle-income countries is an essential component of HIV quality management. In addition, analysis of data, at all levels of the health system, is key to

\footnotetext{
${ }^{1}$ https://healthqual.ucsf.edu/sites/healthqual.ucsf.edu/files/HEALTHQUAL\%20OA_ February\%202018.pdf
} 
improve patient care and outcomes and to facilitate evidence-based decisionmaking. Increasingly, developing countries throughout the world are adopting electronic data collection systems as an effective strategy to improve care with the limited resources available (Forster et al. 2008). iSante offers real-time access to patient data to guide decision-making at the individual patient, facility, and national levels. In many contexts, data are collected but not used due to lack of knowledge, data quality issues, or both. Successful improvement of HIV care and treatment programs requires actionable data, and knowledge and skills for analysis and reporting.

In 2008, additional PEPFAR funding became available to design and deploy an electronic medical record (EMR) for Haiti's HIV care and treatment program, building on and improving upon the existing paper-based record. The MSPP collaborated with the CDC Global AIDS Program, through its implementing partners, to develop an EMR as a coordinated strategy to ensure access to real-time data that could be used for improvement. The national quality Core Team and the team tasked with developing the EMR collaborated to ensure that the system was equipped to address the needs of the nascent HIV quality management program.

A development team (comprised of an electrical engineer, database specialist, programmer analyst, and network specialist) then developed the system using the paper patient record designed by the MSPP and CDC-funded implementing partners. They programmed the system using a software bundle comprised of free and open-source software (LAMP: Linux OS, Apache web server, MySQL database, and PHP scripting language). Development and programming of the system took approximately 1 year, split into three phases (Fig. 4.1).

A task force comprised of key staff from the MSPP, the national program, and implementing partners developed and defined indicators, chose the pilot facilities for rollout of the EMR, and developed an organizational system to maintain

Phase 1 ( 4 months) Refine paper-based HIV medical forms

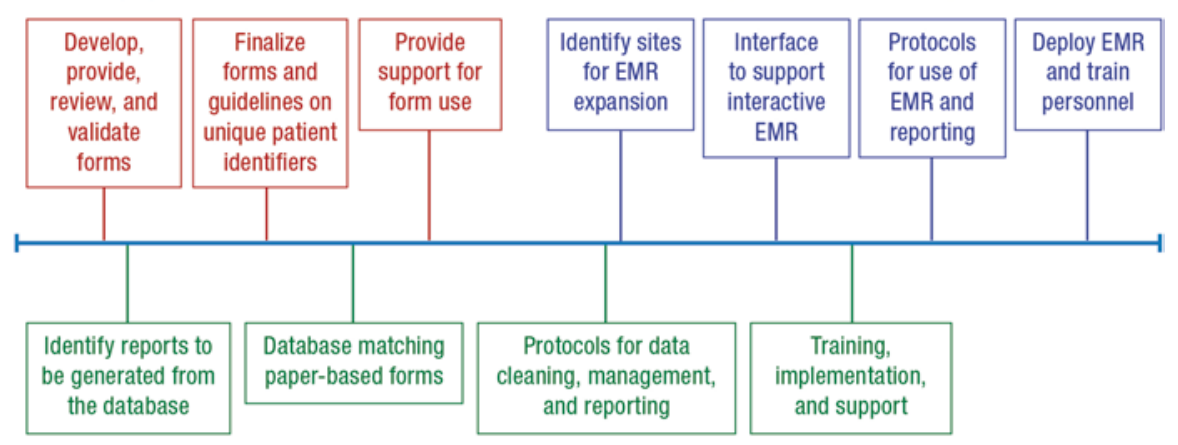

Phase 2 ( 9 months)

Fig. 4.1 Timeline for development and implementation of the EMR system in Haiti 
oversight. The task force initially selected and programmed 19 indicators into the EMR, covering HIV treatment, tuberculosis, maternal and newborn health, nutrition, and immunization, to assess the quality of care (based on national guidelines) received by HIV patients (Appendix 1).

The new electronic medical record, iSanté, facilitated data collection and analysis through its built-in capacity to integrate and extract QI data, accelerating national and local quality improvement work. iSanté was designed to address challenges associated with paper patient records and to streamline separate data collection and reporting processes; it eases constraints associated with formatting data for reporting by automating reports of QI measures. iSanté has improved data integrity through automation and data security, including redundant data back-up, and it facilitates the searching, analysis, and sharing of information. This, in turn, supports health-care workers and clinics to manage and utilize patient data and facilitates timely and accurate reporting. Since iSanté was first implemented, its mandate has been expanded beyond HIV to also include primary health-care and women's health consultations in the same facilities.

\section{Using Electronic Medical Record Data for Improvement}

In each of the health-care facilities where iSanté is in use, the trained data manager, or Disease Reporting Officer, is responsible for data entry, data reconciliation, and reporting. At most of these facilities, iSanté is used at point of care in real time, and data entry is completed directly by a health-care worker. Technical issues will occasionally require facilities that operate iSanté at point-of-care to temporarily revert to paper charts. Once a given problem is fixed, a task force is formed to clear the back$\log$ while reverting to data collection at the point-of-care.

Data managers, or Disease Reporting Officers, generate routine reports on select indicators, which can be easily produced daily, weekly, monthly, quarterly, or annually via preprogrammed reports embedded in iSanté. Daily, the data manager reviews iSanté for data entry errors and reports back to the appropriate health-care worker for reconciliation. Missed visits are displayed in a visit report provided to the MSPP-coordinated community team for patient follow-up. Monthly reports are generated by the site coordinator or other QI staff to evaluate performance progress in core areas of care based on facility and/or national priorities. Monthly clinic-level data reports are printed and shared with all service staff and facility leadership and can be generated by any health-care worker or member of the QI team.

Reports communicate performance scores for all performance measures. Performance scores are reviewed and discussed during regular QI team or staff meetings and during QI committee meetings, where gaps in care and improvement strategies are identified. Regular and immediate access to data through iSanté is used by QI teams and other facility staff to continually monitor effectiveness of improvement interventions and to adapt as needed. 
Performance data are reviewed, analyzed, and validated at the national level by the MSPP during each semester of the fiscal year. This process is designed to identify gaps in particular performance measures across health-care facilities and to inform national priorities for improvement. Semiannual national meetings of the MSPP-coordinated Core Team focus on routine evaluation and analysis of performance trends across all 19 national performance indicators by health-care facility and department within the most recent 6-month data collection period. This group of stakeholders-including MSPP delegates, staff of the national HIV program, and implementing partners - sets benchmarks for the next review period, identifies weaknesses and gaps in the public health-care delivery system, and provides feedback about quality management implementation at the clinic level. This feedback is presented to regional leadership in the geographic Departmental Directorates, who are responsible for communicating with regional coaches, who work with the facilities directly to implement improvement work based on these priorities and areas of need.

Because iSanté includes longitudinal data on all care received by patients in participating health facilities, sampling of data for improvement is not needed; performance measures are calculated based on the patient universe. The system is designed to produce multiple retrospective or prospective reports that generate case lists for appointment, lab test, and care reminders which can be used at all levels: clinic, department, and national. Mechanisms are in place to ensure patient confidentiality is protected. Patients are identified by a code, patient ID, and date of visit in the EMR; they are not identified by name. Access to patient records is only available by care team staff at the particular facility where a patient receives care, with access authorization required for each iSanté user (e.g., username and password).

\section{Measuring Improvement and Results}

\section{Use of the EMR at National and Clinic Levels to Improve Quality}

iSanté has been instrumental in optimizing use of available performance data for improvement, particularly through real-time access to patient data and automation of processes, including reporting, associated with systematic care delivery.

Between January 2008 and March 2014, Haiti's quality management program collected 13 rounds of data using the EMR, measuring care across nine indicators. In each case, performance improved between baseline (collected January to June 2008) and follow-up (October 2013 to March 2014) (Table 4.1). Complete definitions of these and other indicators are found in Appendix 1.

Electronic prompts programmed into the EMR represent a principal factor in facilitating systematic attention to core areas of care (Table 4.2). These include 
Table 4.1 Mean clinic scores by round of data collection and indicator

\begin{tabular}{l|rl|ll}
\hline & \multicolumn{3}{|l|}{$\begin{array}{l}\text { January to June 2008 } \\
\text { Indicator }\end{array}$} & $\begin{array}{l}\text { October 2013 to March } \\
2014 \\
\text { eligible patients }\end{array}$ \\
\hline Clinical visits & $76 \%$ & $11 \mid 3111$ & $80 \%$ & $95 \mid 58,264$ \\
\hline Antiretroviral therapy (ART) & $45 \%$ & $11 \mid 2520$ & $71 \%$ & $95 \mid 9723$ \\
\hline ART adherence assessment & $29 \%$ & $11 \mid 2134$ & $79 \%$ & $94 \mid 44,181$ \\
\hline $\begin{array}{l}\text { Tuberculosis (TB) clinical } \\
\text { screening }\end{array}$ & $29 \%$ & $16 \mid 2990$ & $93 \%$ & $93 \mid 5453$ \\
\hline Nutrition evaluation & $77 \%$ & $16 \mid 8912$ & $86 \%$ & $94 \mid 56,422$ \\
\hline Family planning & $6 \%$ & $16 \mid 5238$ & $51 \%$ & $94 \mid 30,730$ \\
\hline ART for pregnant women & $32 \%$ & $16 \mid 289$ & $91 \%$ & $84 \mid 867$ \\
\hline
\end{tabular}

Table 4.2 Use of the EMR to identify areas for improvement and improvement tracking

\begin{tabular}{|c|c|c|}
\hline $\begin{array}{l}\text { Project } \\
\text { types }\end{array}$ & EMR prompts & Changes related to EMR prompts \\
\hline \multirow[t]{2}{*}{ All } & \multirow{2}{*}{$\begin{array}{l}\text { Performance report for } \\
\text { quality management } \\
\text { program }\end{array}$} & $\begin{array}{l}\text { Use of EMR performance reports to identify low- } \\
\text { performance indicators for QI projects }\end{array}$ \\
\hline & & $\begin{array}{l}\text { Use of EMR performance reports to monitor success of } \\
\text { interventions during PDSA cycles and at the end of QI } \\
\text { projects }\end{array}$ \\
\hline \multirow[t]{3}{*}{$\begin{array}{l}\text { Retention } \\
\text { in care }\end{array}$} & $\begin{array}{l}\text { - Active/inactive } \\
\text { patients }\end{array}$ & $\begin{array}{l}\text { List of active and inactive patients for tracking and } \\
\text { follow-up }\end{array}$ \\
\hline & $\begin{array}{l}\text { - Quality of care report } \\
\text { - Appointment reminders } \\
\text { - Visits scheduled next } \\
7 \text { days }\end{array}$ & $\begin{array}{l}\text { List of patients expected at clinic visits for the week to } \\
\text { follow up with missed appointments }\end{array}$ \\
\hline & $\begin{array}{l}\text { - } \text { Quality of care report } \\
\text { - } \text { CD4 information } \\
\text { - CD4 rates }\end{array}$ & $\begin{array}{l}\text { Patients status: } \\
\text { List of active and inactive patients on ARVs; list of } \\
\text { patients at risk of discontinuation of their medications, } \\
\text { inactive in clinic, or discontinued care at clinic } \\
\text { Used for updating CD4 tests and tracking ART eligible } \\
\text { patients }\end{array}$ \\
\hline $\begin{array}{l}\text { ART } \\
\text { enrollment }\end{array}$ & $\begin{array}{l}\text { - Quality of care } \\
\text { - Appropriate treatment } \\
\text { indicators } \\
\text { ART enrollment } \\
\text { among medically } \\
\text { eligible }\end{array}$ & $\begin{array}{l}\text { List of patients eligible for ART } \\
\text { List of eligible patients enrolled on ART }\end{array}$ \\
\hline
\end{tabular}

automated reporting of indicators to identify low performance in specific measures and use of iSanté-generated performance reports to monitor progress in improvement interventions across PDSA cycles and at the end of specific projects. Other examples include real-time access to active patient lists for tracking and retention, identification of inactive patients and patients at risk of medication discontinuation, and identification of patients eligible for and/or enrolled on ART, among others. 


\section{Improvement Snapshot: iSanté and Prevention of Mother-to-Child Transmission of HIV}

When an HIV-positive woman becomes pregnant, she needs clinical services during her antenatal care to prevent transmission of HIV to her baby. When an HIV-positive woman does not receive these services, such as antiretroviral treatment and adherence support, the likelihood of her HIV-exposed infant being infected is very high, but when antiretroviral therapy is provided to the mother during pregnancy, the mother-to-child transmission rate for HIV can drop to under 5\%, which is the global target set by WHO.

National priorities in the areas of prevention of mother-to-child transmission of HIV (PMTCT) and family planning for HIV-positive women have demonstrated notable improvement in Haiti through immediate access to performance data. For example, clinical performance measurement data for PMTCT tracked nationally through iSanté between January and June 2008 for 16 clinics demonstrated notable gaps in adherence to national PMTCT standards. On average, only $32 \%$ of eligible patients were receiving ART prophylaxis, appreciably under the national benchmark of $100 \%$ for HIV-positive pregnant women.

As a result of this observed gap in care, which became possible through routine iSanté reporting, the MSPP initiated a coordinated campaign through their national HIV quality management program. In 2011, the eligibility definition for ART in pregnant women was changed from gestational age $>28$ weeks to $>14$ weeks (or 98 days from the date of last menstrual period). As of March 2012, the MSPP adopted Option B+ requiring all HIV-positive pregnant women to be systematically placed on ART.

At the clinic level, improvement teams reviewed and analyzed data from iSanté to set facility-specific priorities for improving PMTCT based on gaps identified using EMR data and causes identified using root cause analysis. They then selected interventions for pilot testing, assessed the impact of their changes, modified systems, or tested new changes and immediately integrated tested improvements into daily work by engaging staff and patients. Some interventions implemented at the clinic level included revision and dissemination of PMTCT guidelines to all staff involved in the care process, introduction of female case managers in all clinics to follow up on care of HIV-positive pregnant women, routine tracking of HIV-positive pregnant women by field agents in the community to re-engage patients in care, and early dispensing of ART to HIV-positive pregnant women.

Clinic-level obstacles to routine, consistent, and timely data entry were addressed to reinforce those systems. This included MSPP-supported QI coaching to clinic teams with annual on-site retraining on the EMR and correct data entry procedures, improving EMR access at point of care, institutional focus on immediate data entry directly into the EMR on day of care or directly after each patient visit, and systematic data entry of obstetrics-gynecology and pharmacy forms in iSanté.

The priorities identified at the national level and the changes in care initiated at the facility level to address these priorities have led to a marked improvement in the 


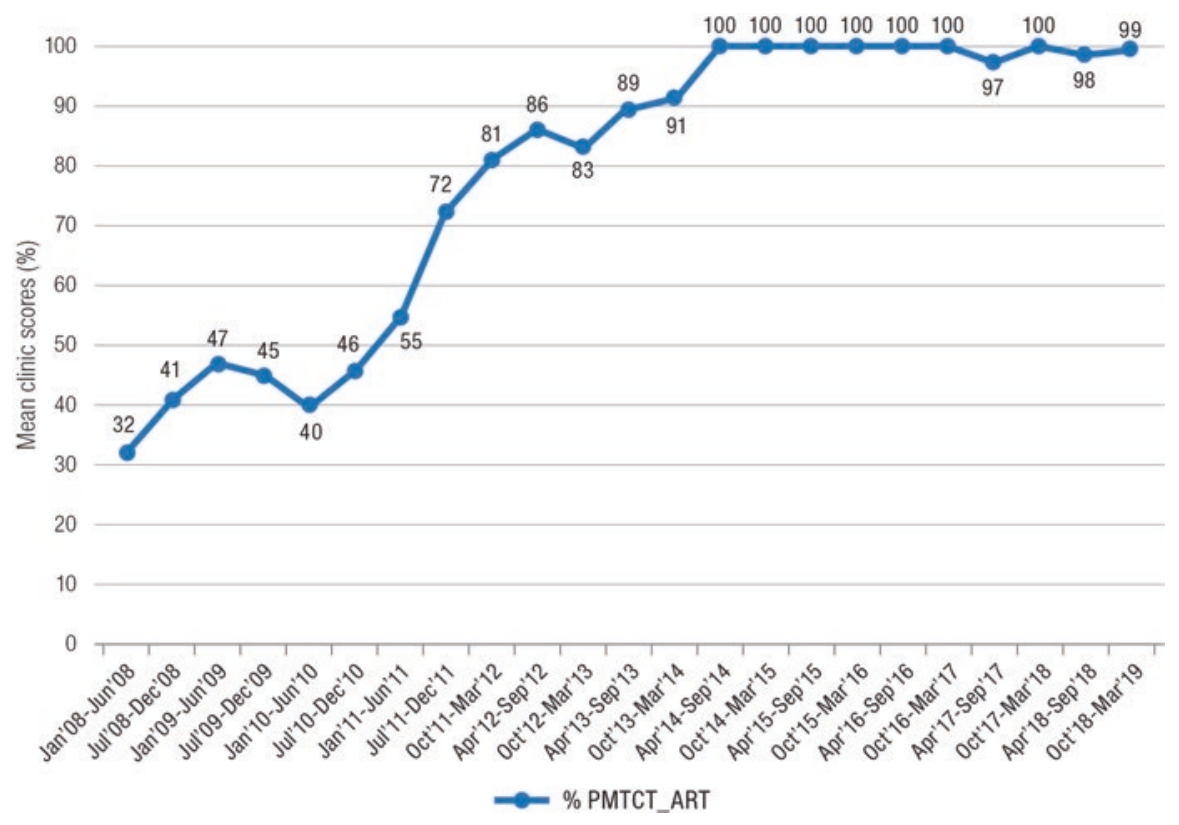

Fig. 4.2 ART enrollment for pregnant women (\%) by review period, January 2008 to March 2019

number of HIV-positive women receiving appropriate care during pregnancy. Overall performance of the indicator measuring the percentage of HIV-positive pregnant women enrolled on ART has improved from an aggregate mean of $32 \%$ in January-June 2008 to an average of above $99 \%$ across review periods through March 2019 (Fig. 4.2). Since ART adherence during pregnancy is associated with reduced transmission of HIV to newborns, this improvement was likely associated with fewer HIV infections among infants born to HIV-positive mothers.

\section{Health Facility Improvement Snapshot: Addressing Lost-to-Follow-Up at Bernard Mevs Hospital}

Bernard Mevs Hospital is located in western Haiti, in the town of Delmas, serving a catchment area that includes Haiti's capital, Port-au-Prince, and the neighboring counties of Delmas, Simmons, Cité Soleil, and other low socioeconomic populations in the region. Hospital services include surgery, pediatrics, family medicine, urology, orthopedics, critical care units, and HIV. There are 1956 active persons living with HIV (PLHIV) in care at the facility.

In January 2018, a facility performance review of data from iSanté revealed that only 74\% of PLHIV were retained on highly active ART (HAART) at 12 months. As a result, a QI project team comprised of a social worker, a data-reporting officer, 
a community field agent, a pharmacist, a data clerk, and the HIV program coordinator was convened to analyze gaps in performance and propose changes based on their findings.

The QI team, as part of robust process improvement activities, used data from tracking of lost-to-follow-up to identify root causes of poor retention. Seven primary factors were identified and quantified during that analysis, including:

- Patients who were too sick to come to facility

- Patients who transferred to another facility

- Lack of resources for transportation to the facility

- Patients seeking alternative care

- Dissatisfaction with hospital services

- Interurban travel

- Work-related barriers

A series of changes, based on the causes identified, were then tested on the February 2017 cohort. First, the list of patients enrolled on HAART in February 2017 was extracted from the EMR with their 12-month retention status. Next, patients who were not active on HAART at 12 months were telephoned or tracked in the community using community navigators. Then, on a case-by-case basis, HAART delivery was adapted to the meet individual patients' needs. For example, for patients who experienced difficulty making routine visits to the hospital, multimonth dispensing of ART or community delivery of HIV drugs (at patient's home or meeting point) was implemented.

Of 12 PLHIV enrolled on HAART 12 months who were lost to care prior to the intervention, 11 were found and 1 was declared deceased. Of the 11 PLHIV found, 2 received community delivery of ARVs and 9 received multimonth dispensing. This strategy facilitated the increase of 12-month retention from $74 \%$ at baseline in January 2018 to $92 \%$ at follow-up in February 2018. The intervention was subsequently scaled up to the broader patient population of PLHIV at Bernard Mevs, where improvement has been sustained at or near 100\% through March 2019 (Fig. 4.3).

\section{Reflection}

Real-time access to patient-level, facility-level, and aggregate national-level data through iSanté has proved invaluable in supporting implementation of Haiti's MSPP-led national quality management program. With immediate access to data at the local level, and with support from national improvement coaches, improvement teams have the capability to quickly review and analyze data for improvement, assess performance of small-scale tests of change, and make adjustments to efficiently maximize effectiveness of QI activities. Nationally, production of aggregate data reports has facilitated identification of gaps in 


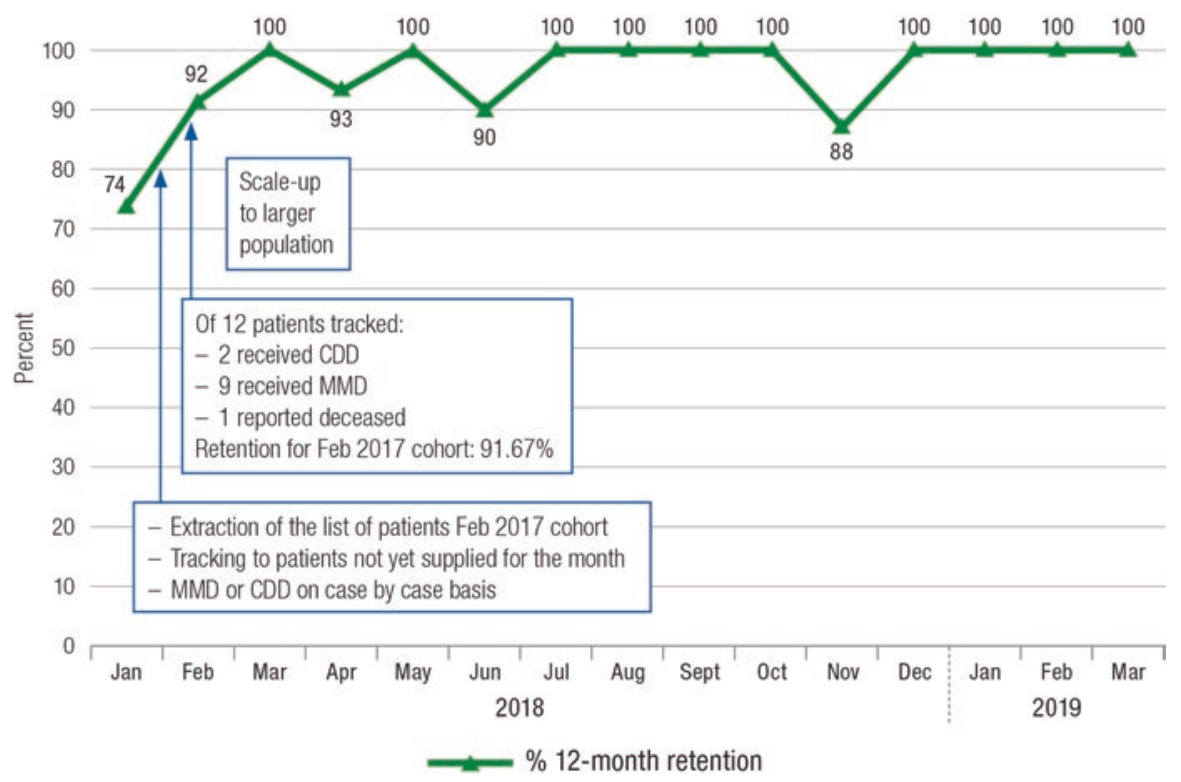

Fig. 4.3 Hospital Bernard Mevs 12-month retention on HAART

care-geographically and/or by area of care-which can be easily displayed for decision-making. This information is routinely used to inform national priorities and reinforce critical areas of care nationwide.

Through Haiti's coordinated national quality management program, which is characterized by strong leadership support from the MSPP, the electronic medical record has facilitated timely access to data for national improvement prioritization in multiple core areas of HIV care. Over the last decade, these have included prevention of mother-to-child transmission of HIV, co-trimoxazole prophylaxis, antiretroviral therapy, and family planning for HIV-positive women, among others.

Among the implementation challenges are familiar issues confronting low- and middle-income countries - issues that were exacerbated considerably in Haiti during these years due to multiple natural disasters, particularly the January 2010 earthquake that devastated much of the island's physical infrastructure and led to the death and displacement of hundreds of thousands of people. Deficiency in local infrastructure, particularly inconsistent access to electricity and information technology networks necessary to operate the EMR, has been one challenge to implementation. Nevertheless, the MSPP mitigated these issues at the onset by establishing local servers at 53 of the 108 iSanté clinics and hospitals and generators at all iSanté-equipped facilities, thus alleviating challenges associated with slow internet connections and facilitating automatic replication of patient data to a central data repository to ensure that patient information is not lost during power outages or natural disasters. 
Successful exploitation of iSanté also relies on trained health-care staff within the MSPP for national deployment and support, as well as human resource capacity at the health-care facility level for daily operation of the system. Development of, and access to, an electronic medical record system is simply not sufficient; knowledge and capability for consistent and accurate data entry, analysis, and reporting are critical. The importance of local coaching support must be emphasized; coaches work directly with each facility to ensure that national priorities are understood, that QI knowledge and skills are reinforced among QI teams, and that data are routinely used to improve patient care.

The implementation of iSanté is an exceptional example of how real-time EMR data can be harnessed and used for improvement, which is even more extraordinary given the setting and multiple natural disasters confronted in Haiti over the last decade. Development and deployment of iSanté represent a unique step in improving the quality of patient care in Haiti and underscore the accomplishments of the national HIV quality management program in introducing and spreading improvement concepts around data use and analysis for quality improvement nationally. This includes noteworthy coordination and buy-in from the Government of Haiti, HIV program leadership, stakeholders, and the multiple partners and donor agencies whose support was vital for success in building technical capacity and management processes for implementation within the context of a national quality program.

Acknowledgments The authors appreciate the support provided by the Haiti Ministry of Health; the National HIV Program; the MSPP HIV QI team; Regional Coaching Teams; CDC-Haiti; the Health Resources and Services Administration; I-TECH; Kathleen Clannon; and Joan Monserratte.

\section{Appendix 1. iSanté Indicators}

\begin{tabular}{l|l}
\hline Current HIV indicators in iSANTE & Definition \\
\hline Patient retention in ART care & $\begin{array}{l}\text { Percentage of HIV-positive patients on ARV treatment in } \\
\text { progress excluding transferred }\end{array}$ \\
\hline Isoniazid prophylaxis & $\begin{array}{l}\text { Percentage of HIV-positive enrolled patients who } \\
\text { received isoniazid prophylaxis during the analysis } \\
\text { period, excluding patients with active TB, deceased and } \\
\text { transferred children under 1 year of age and exposed } \\
\text { children }\end{array}$ \\
\hline ART enrollment & $\begin{array}{l}\text { Percentage of HIV-positive patients enrolled on ART } \\
\text { during the analysis period excluding deceased and } \\
\text { transferred and exposed children }\end{array}$ \\
\hline $\begin{array}{l}\text { Proportion of HIV-positive patients } \\
\text { receiving ARV therapy for more than } \\
6 \text { months with undetectable viral load }\end{array}$ & $\begin{array}{l}\text { Percentage of HIV-positive patients who have been on } \\
\text { ART for more than 6 months with the most recent } \\
\text { undetectable viral load }\end{array}$ \\
\hline
\end{tabular}




\begin{tabular}{l|l}
\hline Current HIV indicators in iSANTE & Definition \\
\hline $\begin{array}{l}\text { Proportion of children exposed to } \\
\text { chain reaction test during the analysis } \\
\text { period }\end{array}$ & $\begin{array}{l}\text { Percentage of children exposed to HIV aged 4 weeks to } \\
18 \text { months whose most recent polymerase chain reaction } \\
\text { test is negative during the analysis period }\end{array}$ \\
\hline PMTCT & $\begin{array}{l}\text { Percentage of HIV-infected pregnant women who } \\
\text { received triple ARV therapy during the analysis period, } \\
\text { excluding deceased and transferred }\end{array}$ \\
\hline Patient retention at 12 months & $\begin{array}{l}\text { Percentage of adults and children who are still on ARV } \\
\text { treatment } 12 \text { months after the start of ARVs, excluding } \\
\text { transfers and exposed children }\end{array}$ \\
\hline Adherence assessment & $\begin{array}{l}\text { Percentage of HIV-positive patients on ARVs who have } \\
\text { benefited from the pills account or completed the } \\
\text { questionnaire in the last 6 months, excluding deceased } \\
\text { and transferred and exposed children }\end{array}$ \\
\hline Level of adherence & $\begin{array}{l}\text { Percentage of HIV-positive patients enrolled on ARVs } \\
\text { older than 3 months with ART adherence level } \geq 95 \%, \\
\text { excluding deceased and transferred and children exposed }\end{array}$ \\
\hline TB screening & $\begin{array}{l}\text { Percentage of HIV-positive patients assessed for TB } \\
\text { during the analysis period, excluding deceased and } \\
\text { transferred, children under 6 months and children } \\
\text { exposed }\end{array}$ \\
\hline $\begin{array}{l}\text { Proportion of HIV-positive patients } \\
\text { receiving ARV therapy who received } \\
\text { an monsessment of their viral load at }\end{array}$ & $\begin{array}{l}\text { Percentage of HIV-positive patients who have been on } \\
\text { ARVs for more than 6 months, with the most recent viral } \\
\text { load result in the last 12 months compared to the end } \\
\text { date of the test period, excluding deaths and transfers } \\
\text { and children exposed }\end{array}$ \\
\hline $\begin{array}{l}\text { Percentage of children aged } 4 \text { weeks to 1 year who } \\
\text { received the early polymerase chain reaction test at any } \\
\text { time before the end of the test period }\end{array}$ \\
\hline
\end{tabular}

\section{References}

Agins BD, Young MT, Ellis WC, Burke GR, Rotunno FF (1995) A Statewide program to evaluate the quality of care provided to persons with HIV infection. Jt Comm J Qual Improv 21(9):439-456

Forster M, Bailey C, Brinkhof MWG, Graber C, Boulle A, Spohr M et al (2008) Electronic medical record systems, data quality and loss to follow-up: survey of antiretroviral therapy programmes in resource-limited settings. Bull World Health Organ 86:939-947. https://doi. org/10.2471/BLT.07.049908

Langley GJ, Moen R, Nolan KM, Nolan TW, Norman CL, Provost LP (2009) The improvement guide: a practical approach for enhancing organizational performance, 2nd edn. Jossey-Bass, San Francisco 
UCSF-HEALTHQUALa. HEALTHQUAL. Found at: https://healthqual.ucsf.edu/. Accessed 20 Aug 2018

UCSF-HEALTHQUALb. Coaching Certification Program. National Quality Management Program

Guidance. Found at: https://healthqual.ucsf.edu/sites/healthqual.ucsf.edu/files/Coaching\%20

Certification\%20booklet10online.pdf. Accessed 20 Aug 2018

UNAIDS (2016) Found at: http://www.unaids.org/en/regionscountries/countries/haiti. Accessed 20 Aug 2018

Open Access This chapter is licensed under the terms of the Creative Commons Attribution 4.0 International License (http://creativecommons.org/licenses/by/4.0/), which permits use, sharing, adaptation, distribution and reproduction in any medium or format, as long as you give appropriate credit to the original author(s) and the source, provide a link to the Creative Commons licence and indicate if changes were made.

The images or other third party material in this chapter are included in the chapter's Creative Commons licence, unless indicated otherwise in a credit line to the material. If material is not included in the chapter's Creative Commons licence and your intended use is not permitted by statutory regulation or exceeds the permitted use, you will need to obtain permission directly from the copyright holder.

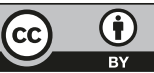

